\title{
THE IMPORTANCE OF INFORMATION SHARING AUTOMATION FOR UNIVERSITY TIMETABLE PLANNING
}

\author{
ABU BAKAR MD SULTAN, NAJLAA ATEEQ MOHAMMED DRAIB
}

\begin{abstract}
University timetable planning is one of the major management activities for any universities in the world. The quality of the timetabling would ensure the smooth registration process by students and avoided unnecessary adjustment. The quality of university timetable is determined by the degree of soft constraint satisfied while hard constraints cannot be compromised. Timetabling problem is the classic problem for computer science domain. Over the past three decades many research has been carried but mostly focusing on the methods or techniques rather than information sharing. Heuristics approaches such as evolutionary computing was the most appeared in literatures. The complexities and size of the problem depends on many factors such as total number of courses from different departments, and resources such as lectures, rooms and timeslots. The cross departmental academic courses registration increases the complexity that requires good communication to avoid missing courses that supposed to be included and the occurrence of redundancy for courses scheduling. This paper present the issue of information sharing for timetabling problem and outlined some automation efforts that potentially employed to overcome communication gap among course providers within university. The initial study was conducted at Faculty of computer Science and Information Technology Universiti Putra Malaysia (UPM) to determine the communication problems during timetable planning and automation method was proposed to reduce the communication gap. The automation method was simple system to gain more insight on the importance of information sharing for the timetable planning.
\end{abstract}

ABU BAKAR MD SULTAN,

Faculty of Computer Science and Information Technology Universiti Putra Malaysia

NAJLAA ATEEQ MOHAMMED DRAIB Faculty of Computer Science and Information Technology Universiti Putra Malaysia
The automation allowed autonomous information sharing with little or no human intervention thus reducing human error during timetable planning. The observation results obtained was promising and future direction is to investigate various intelligence techniques such as agent and workflow technologies for addressing information sharing for timetable problem. Keywords- Information Sharing, University Course Timetabling, Sharing Academic Resources, Autonomous Software, Web-Based Decision Making Supporting Tool

\section{Introduction}

University timetabling planning is one of the major management activities for any universities in the world. The quality of the timetabling would ensure the smooth registration process by students and avoided unnecessary adjustment. University course timetable planning consisting of managerial activities to schedule a set of given resources (lecturers, students, classrooms) to objects (courses) in a cyclic period of time satisfying a number of university constraints. Constraints were classified into hard and soft constraints. Hard constraint must be satisfied while soft constraints indicated the quality of timetable. Timetabling is a classic problem for Computer science. Over the past three decades many research has been carried and mostly focusing on techniques and methods particularly on the heuristic approaches. However not many literatures addressing the issues of information sharing during timetable planning.

Universities in which students are divided into groups, courses for each group of students are predefined and assigned to academic semesters. In this case, choosing a course is not important and timetabling is almost repeated for every academic year with minor adjustments if needed. Scheduling timetable is more difficult in developed course choosing, where each student can choose a number of relevant courses from his departments and outside departments and faculties as well. In circumstances course scheduling is changed for each academic semester. 
Typically, during course timetable planning, university's departments potentially need to request one or more courses from other departments at the same campus. In this case, there is a significant need of such information sharing system for exchanging information between these departments so that they use each other's data for making decisions and creating their own scheduling.

The Software Engineering department in the Faculty of Computer Science and Information Technology at Universiti Putra Malaysia still uses a manual process for scheduling courses. It is not able to exchange relevant information automatically with the other departments. At present, the information sharing takes place verbally among the heads of departments, schedulers, or persons that create the course timetable.

For the sake of improving information asymmetry in timetabling planning at universities and keeping information sharing efficiently communicated among university departments and faculties, current manual system of information sharing in the Faculty of Computer Science and Information Technology must be changed into automatic information sharing system that will make information symmetrical to each department.

This paper highlighted the importance of information sharing automation for timetable planning. The case study was conducted to the timetable planning at Faculty of Computer Science and Information Technology, Universiti Putra Malaysia and a prototype (Timetabling Decision Making Supporting Tool (TDMST)) was developed. This tool enhances information sharing and cooperation between university departments by automating the information flow for the process of building course timetable. The proposed tool is smart enough to give suggestions, help in decision making, and automatically send feedback between the departments.

This paper is organized into six sections. Introduction to course timetabling is in section 2 . Section 2 is discussing the importance of information sharing. Section 3 sheds light on the prototyping of the proposed solution. Section 4 and 5 discuss the result and the conclusion respectively.

\section{Information Sharing}

Sharing resources has a significant importance in public and private sectors due to its advantages to cut cost (time, money, and efforts) required to achieve goals. Information is one of the most important resources to be shared. For public government organizations, sharing information across organizational boundaries is an essential factor to accomplishing public benefits such as increased productivity, improved policymaking and integrated public services[2].

In academic environment, whenever resources are usable and sharable, there is a desire by the different departments to benefit from sharing or /and exchanging these resources either for their selfish interest or to be helpful with the other departments in the same campus. Typically, the process of sharing or exchanging resources includes sharing information about these resources.

Timetabling potentially involves scheduling courses shared from other departments. Indeed, requesting or providing these courses cannot be achieved without sharing/exchanging related information.

Information sharing has been defined as an act of exchanging information among community members who are in need of those information [3]. Therefore, information sharing may involves multiple parties who share information of common interest.Those information are in the form of suggestions, opinions and answers to questions [4]. Basically, automated information sharing decreases paperwork burden, work processes and enhances "the formulation, implementation, and evaluation of policy" [5]. Management staff deliberately share information related to work and key developments and activities [6].

Although the issue of information sharing and information sharing systems are discussed a lot in literature, there are not many scholars who have particularly discussed timetabling information sharing system. Therefore, it is hard to find such papers in this research field.

In this paper we discuss the importance of information sharing in course timetabling and we outlines some technologies that could employed to reduce communication gap for timetable palnner.

\section{Timetabling Planning at FSKTM}

The Faculty of Computer Science and Information Technology at Universiti of Putra Malaysia (UPM) consists of four departments, Department of Computer Science, Department of Multimedia, Department of Computer Network, and Department of Software Engineering and Information Systems. These departments offer a four years program for bachelor degree. 
Proc. of the Second Intl. Conf. on Advances in Information Processing and Communication Technology - IPCT 2015

Copyright $(\odot$ Institute of Research Engineers and Doctors, USA .All rights reserved.

ISBN: 978-1-63248-044-6 doi: 10.15224/ 978-1-63248-044-6-15

Timetabling planning was performed every semester for next following semester schedule. It was done by respective department coordinator. Typically coordinator refers to the previous semester timetable and performing some modification based on the available resources such as lectures and courses offered. . The historical data contains the offered courses associated with the experts group (lecturers who taught the course) for each course. In case the course is new, the selection of the lecturer will be based on either the collected information about lecturers' wishes, or based on the specializations of the lecturers. The curriculum structure in FSKTM consists of three categories of courses, university courses, core courses, and elective courses. University courses component contain courses offered to university students to equipped them with communication skills and business management. University courses was offered by outside department with total six courses and compulsory to all degree programs at UPM.

Core courses are a combination of various courses in the department specialization. Core courses sometimes contain a number of courses offered from outside the department (other departments). Elective courses can be selected by the student within the courses offered by department or outside the department. The courses that should be scheduled for department must not only consist courses offered by department but also outside department. It is always happen that during the timetable planning, coordinators are facing difficulty to schedule outside courses to fit their department timetable. This is due to the problem of efficient communication sharing between departments. In this work we focus more on core courses, as they contain some courses offered by outside departments.

In FSKTM's departments, the process of course timetabling can be divided into two stages, schedule courses offered by the department itself and scheduling the courses that must be requested from the other departments. The order of performing these stages is not important. In addition to scheduling of certain number of its own courses and satisfying specific conditions, one university department usually needs to schedule one or more resources (lecturer(s)/room(s)) from other university departments. To be able to schedule these courses, an academic department needs first to send request to another department that offers that resource and exchange relevant information with it. This information is essential for the academic department in order to assign the requested courses to appropriate timeslot in its own courses timetable according to its own constraints.

The information sharing during building timetables in UPM's academic departments still face difficulties in timetable planning due to the lack of information sharing and low level of crossdepartment information sharing. These difficulties restrict and delay the process of timetabling. Figure 1 , illustrates the manual procedure of sharing lecturer between two departments. In this paper, academic consumer represents the department that sends request to share/request a lecturer, whereas academic provider represents the department that offer the requested course.

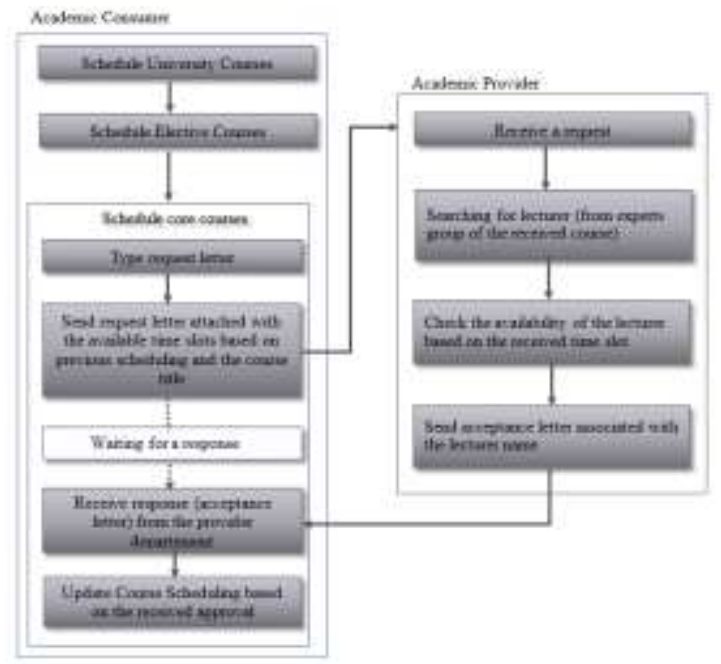

Figure 1: Manual process of booking lecturer

In this work we propose a convenient and efficient information sharing tool to automate the information sharing between UPM departments in timetabling, this tool aims to reduce time and efforts spent on timetable generation. The proposed tool will be applied in timetable planning for the Faculty of Computer Science and Information Technology at the Universiti of Putra Malaysia.

\section{Proposed System Solution}

We proposed autonomous and intelligent supporting tool that focusing on information sharing among university departments during the creation of timetabling stage. This tool is concerned 
Proc. of the Second Intl. Conf. on Advances in Information Processing and Communication Technology - IPCT 2015 Copyright $\odot$ Institute of Research Engineers and Doctors, USA .All rights reserved.

ISBN: 978-1-63248-044-6 doi: 10.15224/ 978-1-63248-044-6-15

with automating the flow of course information, while consisting of timeslot and lecturer among departments.

\section{A. System Description}

This section presents a summary overview of Timetabling Decision Making Supporting Tool (TDMST). This tool is mainly used to enhance information sharing and flow during course timetable planning. For administration purposes, we added some extra functions.

TDMST provides a guidance and supports decision making in course time tabling. This function could be established by enhancing information sharing between academic consumer and academic provider. Additionally, several functions are available for different types of users.

Figure 4.1 presents a general overview of the prototyping

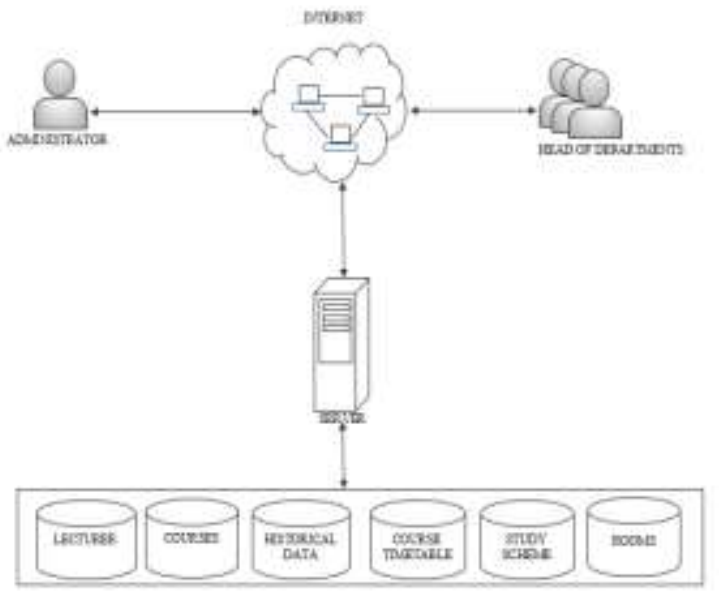

Figure 5.1 general overview of TDMST.

TDMS tool users can be categorized into two categories: administrator and heads of departments (or any user who is responsible for creating course timetable).

Administrator can manage other users' data (add, remove and update) and rooms' data. In addition to updating study scheme and resources (lecturers, courses) data, head of department can build course timetable and response to the other department requests. Building course timetable procedure involves sending a request automatically to other departments with a list of needed lecturers based on study scheme. Simultaneously, a notification email is sent automatically and lecturer historical data is updated.
The area of this project is based on CS department resources dataset (lecturer, courses, course timetable (if it is already generated), study scheme, and historical data) and SE department dataset (lecturer, courses, course timetable (if it is already generated), study scheme, and historical data), in addition to one table stores users data. This data serve the aim of developing TDMS system. All of the information that is necessary to creating course timetable is stored in relational database.

\section{B. System Implementation}

This section gives a detailed look at the system implementation. TDMST provides its user with all the information they need during the process of course timetable planning. In addition, it extracts the related information that is necessary to scheduling courses offered outside the department. One department can represent academic provider and academic consumer at the same time.

The generation of course timetable for a given semester is decomposed into three stages that involves the interaction of the departments. First stage begins with the identification of the courses that will be offered in particular semester. Then, TDMST builds course timetable for local courses that are offered by the department itself. The necessary information is constructed from the database. This information includes the group of experts for each course and the available timeslots for each lecturer in the group. Based on this information, the system allocates lecturer and timeslot to the corresponding courses. Selection of these courses is done based on the information extracted from the study scheme.

Once the scheduling of courses offered inside the department is done, the procedure enters the second phase, here, a number of schedules should be compiled to build a temporary course timetable for those courses offered by other departments (academic providers). The temporary table is built based on information shared between the departments (academic consumer and academic provider). Thus, the system can assign appropriate lecturer and timeslot to a particular course. Once the temporary course timetable is ready, it will be sent autonomously to the academic provider in order to get an approval. Sending the temporary course timetable means that it will be displayed in the academic provider interface whenever the academic provider login into the system. To prompt the academic providers to login to their accounts, TDMST sends an email to the academic provider 
Proc. of the Second Intl. Conf. on Advances in Information Processing and Communication Technology - IPCT 2015 Copyright ( $\odot$ Institute of Research Engineers and Doctors, USA .All rights reserved.

ISBN: 978-1-63248-044-6 doi: 10.15224/ 978-1-63248-044-6-15

simultaneously with displaying the request in the academic provider main interface.

Third stage is to assist the academic provider to make decision. This guidance is provided in the case that the allocation of timeslot or lecturer to the course is not acceptable. In this case, TDMST supports the user by providing him by all the information needed to reallocate the timeslot or lecturer to the requested course. After the submission of the selected lecturer and/or timeslot, TDMST inserts the temporary table records into the courses timetable in the consumer department dataset and then resets the temporary course timetable. In this paper, we supposed that university courses are already scheduled. New allocation of lecturer to course will be added automatically to the historical data. The academic provider can be academic consumer as well, we have used these names to differentiate between the departments for description purpose. Figure 5.3 shows all three stages in course timetable planning.

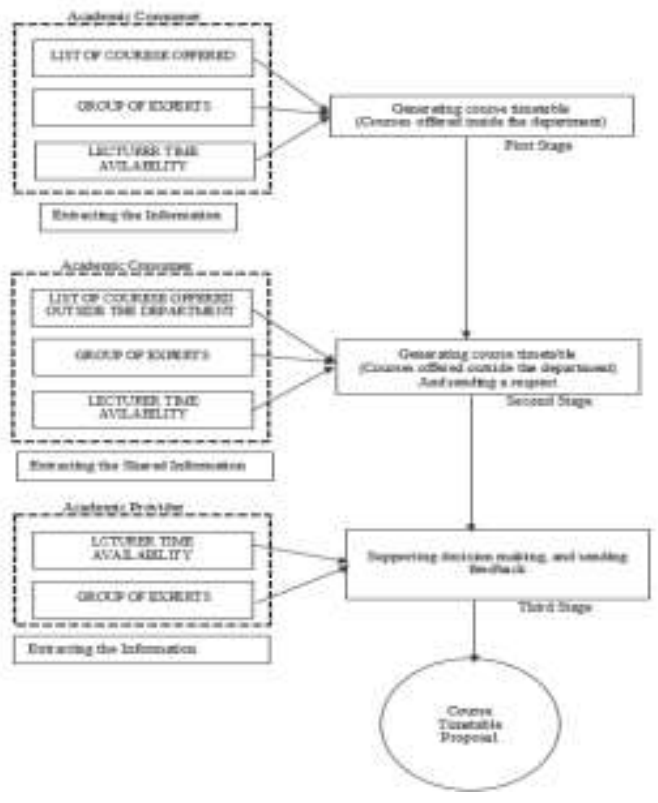

Figure 5.3 the three stages of the course timetable process

\section{Simulation and Results}

Before the implementation of TDMST, timetabling preparation was a tedious process in which repetitive communication among the department coordinator to stimulates the courses, lectures and timeslot to avoid conflict was performed. The process became more difficult if it involves many courses provider from different department. Coordinator should be able to communicate effectively to others in order to prepare their department timetable. Sometimes problem occurred due to communication problem that requires further adjustment. The communication form among the coordinators was email, phone, memo, direct communication or thru official meeting.

With the implementation of TDMST, all form of existing communication was no longer needed and all task was carried autonomously online and at realtime. The role of the coordinator is to ensure all information required for timetabling such as lecture, courses offered was up to date. The coordinator is the person who allocates lectures to courses according to their expertise.

From our observation information sharing automation for timetable planning has led to several benefits. First of all, the time required for generating course timetable has reduced significantly. Second, the work load for schedulers has reduced which makes them free to do other tasks. Third, information sharing in certain stages of course scheduling has successfully automated. Fourth, a new channel of communication between the departments has created which facilitates and accelerates exchanging information between them. Finally, human errors have eliminated which reduces timetable conflicts and improves its quality.

\section{Conclusion}

This study revealed the importance of information sharing and information sharing automation during timetable planning. The case study carried indicates information sharing automation contributed significant impact on timetable quality. Many benefits such as reducing error, redundancy and reducing time was obtained from the case study. The main idea was to allow the system autonomously sharing the information about course timetabling with minimal intervention by human. The case study presented show insight the importance of automated information sharing and we outlined some existing technologies that potentially employed. Such technologies were software agents technologies and workflow technologies. The current communication technologies like web technologies and email could be utilized in agent or workflow.

This work is an ingoing work, and more work has to be done to improvise the presented approach. The aim will be to use software agents approach to improvise the proposed solution. In addition, we plan to extend the solution to involve more than two departments and more academic resources. 
Proc. of the Second Intl. Conf. on Advances in Information Processing and Communication Technology - IPCT 2015 Copyright $\odot$ Institute of Research Engineers and Doctors, USA .All rights reserved.

ISBN: 978-1-63248-044-6 doi: 10.15224/ 978-1-63248-044-6-15

\section{References}

[1] Schaerf A. A survey of automated timetabling. Artif Intell Rev 1999;13 2!:87-127.

[2] Z. Yan, B. Sun, and T. Wang, "A Study on E-Government Information Sharing *," no. 07, 2001.

[3] Gardoni, M., Spadoni, M., \& Vernadat, F. (2000). Harnessing non-structured information and knowledge and know-how capitalisation in integrated engineering: Case study at aerospatiale matra. Concurrent Engineering, 8(4), 281-296.

[4] Rafaeli, S., \& Raban, D. R. (2005). Information sharing online: A research challenge. International Journal of Knowledge and Learning, 1(1), 62-79

[5] Landsbergen Jr., D., Wolken Jr., G.: Realizing the Promise: Government Information Systems and the Fourth Generation of Information Technology. Public Administration Review 61, 206-220 (2001)

[6] Bunderson, J. S., \& Sutcliffe, K. M. (2002). Comparing alternative conceptualizations of functional diversity in management teams: Process and performance effects. Academy of management journal, 45(5), 875-893.

[7] Lee, J., Ma, S. P., Lai, L. F., Hsueh, N. L., \& Fanjiang, Y. Y. (2005). University timetabling through conceptual modeling. International journal of intelligent systems, 20(11), 1137-1160.

[8] Di Gaspero, L., Mizzaro, S., \& Schaerf, A. (2004, August). A multiagent architecture for distributed course timetabling. In Proceedings of the 5th International Conference on the Practice and Theory of Automated Timetabling (PATAT-2004) (pp. 471-474).

[9] De Causmaecker, P., Ouelhadj, D., \& Vanden Berghe, G. (2003). Agents in timetabling problems. In Proc. of the 1st Multidisciplinary International Conference on Scheduling Theory and Applications (pp. 67-71).

[10] Piechowiak, S., \& Kolski, C. (2004). Towards a generic object oriented decision support system for university timetabling: an interactive approach. International Journal of Information Technology \& Decision Making, 3(01), 179-208.

[11] Vincellér, E. C. (2001). Design, development, and formative evaluation of DB-notebook: a prototype computer-based tool to support less skilled readers(Doctoral dissertation, Concordia University).

About Author (s):

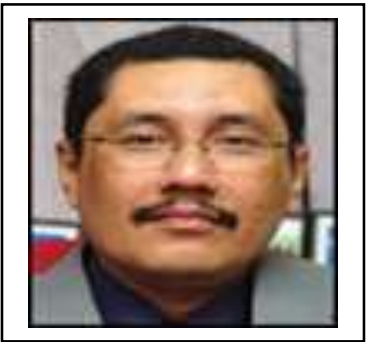

Abu Bakar Md. Sultan holds a PhD in Artificial Intelligence from University Putra Malaysia (UPM) in 2007. His research focus is in Artificial Intelligence and Software Engineering particularly Search-based Software Engineering (SBSE). He has published articles in conferences and various journals related to SBSE. Associate Professor Dr Abu Bakar Md. Sultan currently is the dean of Faculty of Computer Science and Information Technology, Universiti Putra Malaysia 